\title{
Steatocystoma Multiplex of Scortum- Rare Genetic Disorder: A Case Report and Review of Literature
}

\author{
MM SAHA $^{\text {a }}$, S SAHA ${ }^{\text {b }}$, RLD BANIK ${ }^{c}$, MM HOSSAIN $^{d}$
}

Summary:

A 25 years old male attended the skin \& VD outpatient department of Khulna Medical College Hospital on 16th June, 2013 with complaints of multiple asymptomatic small rounded firm, cystic nodules that are adherent to the overlying skin of scortum. The microscopic examination of the cystic nodules showed the features of steatocystoma multiplex. This disorder, although it is asymptomatic, is a

\section{Introduction:}

Steatocystoma multiplex was first described by Jamieson in 1873, and the term was coined by pringle in $1899^{1}$. Steatocystoma multiplex is very uncommon genetic disorder which usually begins in adolescence and early adult life ${ }^{2}$. The condition is inherited as an autosomal dominant in many cases ${ }^{3}$. Both sexes are affected equally ${ }^{4}$. The disease presents with multiple asymptomatic firm cystic nodules on the axilla, groin, trunk, scortum and the proximal extremities because of high density of developed pilosebaceous units and is it rarely localised on the face and the scalp ${ }^{5}$. The sternal region is commonly affected in males. According to the sites the disease is subgrouped into the localized, generalized, facial, acral and the suppurative type. Development of Steatocystoma multiplex has been hypothesized to be due to alteration in the structure of keratin $17^{6}$. Steatocystoma also occurs occasionally as a solitary, non-herited tumour in adults, where it is

a. Dr. Moni Mohan Saha, Professor \& Director, Shaheed Sk Abu Naser Specialized Hospital, Khulna

b. Dr. Sukumar Saha, Junior Consultant, Shaheed Sk Abu Naser Specialized Hospital, Khulna.

c. Dr. Ratan Lal Datta Banik, Junior Consultant, Khulna Medical College Hospital, Khulna.

d. Dr. Md. Mokter Hossain, Assistant Professor, Department of Pathology, Khulna Medical College, Khulna

Address of Correspondence: Dr. Moni Mohan Saha, Professor \& Director, Shaheed Sk Abu Naser Specialized Hospital, Khulna, Received: 23 October, 2013

Accepted: 6 June. 2015 cosmetic threat to the patient. Only a few cases of the patients with an autosomal dominant mutation, who had keratin 17; have been reported. We are reporting here a case of steatocystoma multiplex of scortum in a 25 years old male along with review of literature.

Key words: Steatocystoma multiplex, Genetic disorder.

(J Banagladesh Coll Phys Surg 2015; 33: 218-221)

referred to as steatocystoma simplex ${ }^{7}$. Steatocystoma multiplex present with early dome shaped lesion that are translucent and which change to a yellowish colour with age. The puncta are not obvious but the comedeones are an associated featrue ${ }^{8}$. The spontaneous rupture of the cyst, if it occurs, with result in steatocystoma multiplex suppurativum which is characterised by inflammation and scarring which is reminiscent of acne conglobata ${ }^{9}$.

Details of steatocystoma multiplex perhaps has not yet been reported in our country. Here a rare genetic disorder with autosomal dominant pattern of inheritance in early adult, diagnosed clinically as eruptive vellus hair cyst or epidermal inclusion cyst is reported.

\section{Case history:}

A twenty five years old male attended the skin \& VD out patient department of Khulna Medical College Hospital on $16^{\text {th }}$ June,2013 with the complaints of multiple asymptomatic small firm cystic nodule of scortum of eight month duration. The patient came of an average socio-economic background and his general condition was good. On examination, multiple cystic nodules are found that are small in size vary in diameter from 2 to 5 $\mathrm{mm}$. The cystic nodules are moderately firm, round to oval in shape with well defined and smooth surfaced without a punctum. The cystic nodules are adherent to the overlying skin of the scortum. The patient gave a history of similar lesion in his father too. The systemic and the laboratory findings were normal. Sonography revealed multiple nodules which were relatively well marginated and hypoechoic and with a posterior enhancement. Clinically the differential diagnosis of the 
case was either eruptive vellus hair cyst or epidermal inclusion cyst. Then FNAC and biopsy were advised to confirm the diagnosis. On FNAC, an oily material was aspirated. The stained smear revealed some keratinized squamous cell and occasional anucleated squames scattered in a background of amorphous homogenous eosinophilic material.

On histopathological examination, the dermis revealed a cyst lined with flattened startified squamous epithelium without a granular layer and a cellular eosinophilic cuticle over is surface. The lining stratified squamous epithelium has sebaceous gland lobules within and close to it. The cyst wall also showed intricate foldings. After the histopathological confirmation of steatocystoma multiplex, the patient was given oral isotretinoin and advised for radiofrequency probes at the cosmetic sites of the body but the patient declined further surgical treatment.

\section{Morphological \& cytological findings:}

Gross appearance: Specimen consisted of two nodular pieces of grayish white skin tissue stated to be resected from scortum. The larger one measuring about $2.5 \mathrm{X} 1.6 \mathrm{X} 1.0 \mathrm{~cm}$. It was cystic and firm in consistency. Their surfaces were rough and content occasional hair follicle. The cut surface showed cystic homogenous appearance. Two blocks were made for paraffin embedding.

\section{Microscopic appearance:}

Haematoxylene and eosin stained slide prepared from submitted specimen showed epidermis and dermis. The dermis contained a cyst lined with flattened stratified squamous epithellium without a granular layer and with

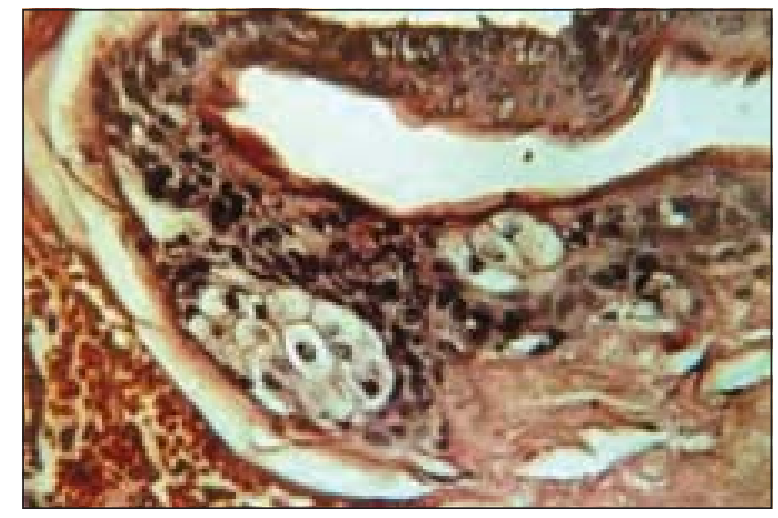

Fig.-1: Sections show a cyst wall lined with flattened stratified squamous epithelium without a granular layer. Many sebaceous glandular lobules are present within the cyst wall. (H\&EX375)

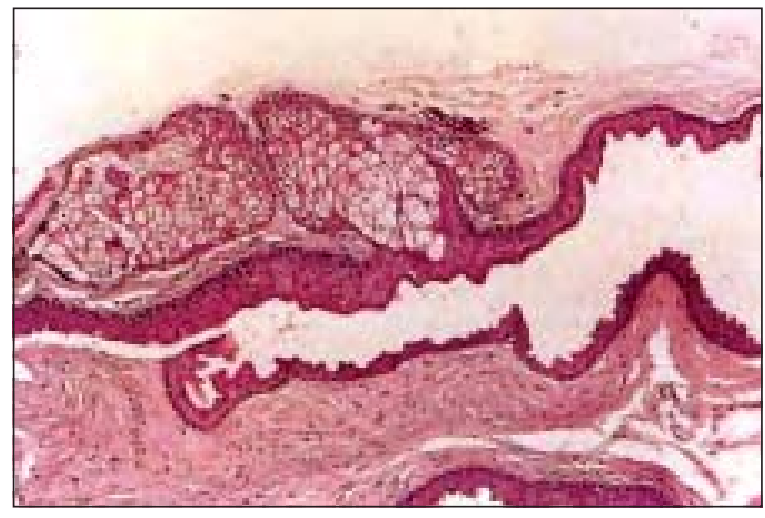

Fig.-2: Sections show cyst wall having intricate foldings. (H\&EX110).

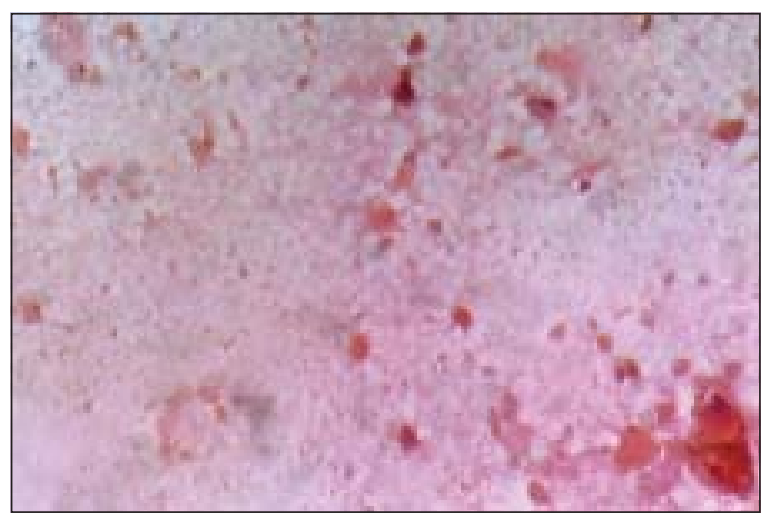

Fig.-3 (FNAC): Paps stained smear shows some keratinized squamous cells and occasional anucleated squames scattered in a background of amorphous homogeneous eosinophilic material.

thick homogenous eosinophilic cuticle over it surface. Many flattened sebaceous glandular lobules were present within the cyst wall. The cyst wall also showed intricate foldings.

\section{Discussion:}

Steatocystoma multiplex is usually appear during adolescence and early adult life and there is no sex predilection. Age of the reported patient was twenty five years which agree with the findings of Mumcuolu CT, Gurel MS, Kiremitci U et al. ${ }^{10}$ The patient presented with multiple asymptomatic firm cystic nodule that are adherent to the overlying skin of the scortum. These features agree with the findings of Hemlata TK, Pradeep AG, Ajay GO, et al. ${ }^{11}$ The exact origin of the cyst is still unknown but multiple theories which suggest their 
origin are: they result from sebaceous retention cyst of a naevoid nature or they are hamartomas or they are a variety of dermoid cyst. Few authors have associated steatocystoma multiplex with ichithyosis and koilonychias, Pachyonychia congenital, acrokeratosis verruciformis of hopf, hypertrophic lichen planus hypohidrosis, hypothyroidism, hidradenitis suppurativa and hypotrichosis. ${ }^{13}$

The familial steatocystoma multiplex is associated with a mutation in the keratin 17 gene, in the areas which are identical to the mutation which are found in patients with pachyonychia congenita type-2 (PC-2). ${ }^{14}$ Uptil now in patients with either steatocystoma multiplex or pachyonychia congenita type-2, 14 mutation have been discovered, all of which are localized to the helix initiation domain (IA domain) of the $\mathrm{K} 17$ gene. The $\mathrm{KRT}_{17}$ gene is located on the long arm of chormosome 17 , between positions 12 and 21 and the mutations in this gene interfere with the assembly of the keratin intermediate filament network. ${ }^{15}$ Smith FJD have reported heterozygous missense mutations in K17 in two families who were diagnosed as steatocystoma multiplex. ${ }^{16}$

In our case, the patient had no features of pachyonychia congenita type-2 such as hypertrophic nail dystrophy, focal keratoderma and multiple pilosebaceous cyst. The relationship of steatocystoma multiplex to the development of sebaceous glands and its common presentation at puberty suggest a hormonal trigger for the lesion growth. ${ }^{17}$ The patterns of keratin 10 (K10) and keratin 17 (K17) expression are also variable in the epidermoid cysts, the trichilemmal cysts, eruptive vellus hair cysts and in steatocystoma multiplex. The epidermoid cysts expressed K10 and the eruptive vellus hair cyst and in steatocystoma multiplex. The epidermoid cyst expressed K10 and the eruptive vellus hair cysts expressed K17, whereas trichilemmal cysts and steatocystoma multiplex showed the expression of both K10 and K17. ${ }^{18}$

On Electron microscopy, steatocystoma multiplex has been found to be a nevoid sebaceous duct and a sebaceous gland tumour. There is one pilary unit which continuously produces the vellus hairs, which are trapped in the cystic cavity or in the pilary cannal (tricostasis). Steatocystoma multiplex is connected to the epidermis by a straight or meandering epithelial cord, the remnant of the follicular infundibulum which is a solid strand which contains sebocytes or sebaceous lobule like structure. A lumen which is partly present in a few areas of the cord, is filled with cellular debris of the keratinocytes, corneocytes, sebocytes or the trapped hairs. ${ }^{19}$ In comparison, the trichilemmal cysts take their origin from the outer root sheath of the follicle, the epidermal cysts take their origin from the infundibulum and the vellus hair shafts take their origin from the infundibuloisthmic junction or the isthmus. ${ }^{20}$

The diagnosis should always be confirmed on histopathology excluding its main differential diagnosis like eruptive vellus hair cyst, epidermal inclusion cyst, milia, trichilemmal cyst and the tumours of the follicular infundibulum. Steatocystomas and vellus hair cysts are closely related to each other. Cases have been published with cysts showing the features of both steatocystoma multiplex and eruptive vellus hair cysts, which are caused by a cystic change in the same pilosebaceous duct. ${ }^{21}$ Eruptive vellus hair cyst show dermal cysts which are lined by stratified squamous epithelium with a granular layer and which contain many obliquely, transversely sectioned vellus hair shafts. The microscopic examination of the expressed contents in a potassium hydroxide preparation shows numerous vellus hairs in the eruptive vellus hair cysts. Generally, no sebaceous glands are present in the cyst wall. The epidermoid cysts are lined with stratified squamous epithelium which contains a granular layer and they show laminated keratin inside the lumen of the cysts. Milia show very small cysts. The milium is usually located in the superficial dermis and it has an epithelial lining with a granular cell layer. It contains laminated keratin: Tumours of the follicular infundibulum show a plate like dermal tumour with anastomosing islands and cords with connections to the overlying epidermis and the horn cysts. The trichilemmal cysts are lined by squamous epithelium without a granular layer and with the swelling of the cells close to the cyst cavity, which is filled with homogenous keratin. But the characteristic histopathological findings of steatocystoma is the presence of sebaceous lobules close to the cystic wall, which is lined by stratified squamous epithelium without a granular layer, though there may be scanty vellus hairs in the cystic cavity.

The various modalities in the treatment of steatocystoma multiplex include surgery, $\mathrm{Co}_{2}$ laser 
therapy, oral isotretinnoin and cryotherapy, but the recent procedures include the use of radiofrequency incision probe to make mini incisions and for expressing the contents of cyst even the cyst wall. It has the advantage of producing blood less field which can not be obtained by surgical blades ${ }^{22}$ and the other advantages are the treatment with the Erybium: YAG laser followed by topical tetracycline ointment which also have shown good cosmetic result. ${ }^{23}$

In conclusion, Pachyonychia congenita type- 2 and the eruptive vellus hair cyst are closely related to steatocystoma multiplex. Therefore a histopathological confirmation is a must before starting with any treatment. The genetic chromosomal abnormalities and mutations should be detected and long term follow up should be taken up in such patient for further research on this disease.

\section{References:}

1. Davey Methew "Steatocystoma multiplex": Retrieved 25 may 2011.

2. Mount LB. Steatocystoma multiplex.Arch Dermatol Syphilol 1992;36:31-9.

3. Noojin RO, Reynolds JP. Familial steatocystoma multiplex: twelve cases in three generations. Arch Dermatol Syphilol 1997; 57: 1013-8.

4. Amerlinck F. Sebocystomatose hereditaire. Arch Belges Dermatol Syphiligr. 1988; 5: 187-91.

5. Kim SJ, Park HJ, Oh ST Lee JY, Cho BK. A case of Steatocystoma multiplex limited to scalp. Ann Dermatol 2009; 21(1): 106-9.

6. Chu DH. Steatocystoma multiplex. Dermatol Online J. 2003 Oct; 9(4):18

7. Brownstein MH. Steatocystoma simplex: a solitary steatocystoma. Arch Dermatol 1982; 118:409.

8. Hurley HJ, Lopresti PJ. Steatocystoma multiplex. Arch Dermatol 1965; 92:110-11.

9. Plewig G, Wolf HH, Braun-Falco O. Steatocystoma multiplex: anatomic reevaluation, electron microscopy and autoradiography. Arch Dermatol Res. 1982; 272(34): 363-80.
10. Mumcuolu CT, Gurel MS, Kiremitchi U, et al. Laser therapy for Steatocystoma multiplex. Indian J Dermatol 2010; 55(3): 300-01.

11. Hemlata TK, Pradeep AG, Ajay GO, et al. Steatocystoma multiplex- A case report and review of literature. J Clinical and Diagnostic Research 2013; January Vol 7 (1): 165168.

12. Lima AM, Rocha SP, Batista CM, et al. What is your diagnosis. Case for diagnosis. An. Bras. Dermatol 2011; 86(1): 165-66.

13. Covello SP, Smith FJ, SillevisSmitt JH, Paller AS, Munro CS, Jonkman MF, et al. Keratin 17 mutations cause either Steatocystoma multiplex or Pachyonychia Congenita type-2. Br J Dermatol 1998; 139(3): 475-80.

14. Chu HD. Steatocystoma multiplex. Online Journal 2003; 9(4):18.

15. Gass JK, Wilson NJ, Smith FJ, Liane EB, McLean WH, Rytina E, et al. Steatocystoma multiplex, Oligodontia and partial persistent primary dentition associated with a novel keratin 17 mutations. Br J Dermatol 2009; 161(6): 1396-98.

16. Smith FJD, Cordon LD, Rugg EL, Ratnavel R, Leigh IM, Moss C, et al. Missense mutations in keratin 17 or either Pachyonychia congenita type-2 or a phenotype resembling steatocystoma multiplex. Journal of investigative dermatology 1997; 108: 220-223.

17. Xiuying W, Yaozhou SHI, Yuexian YE, et al. Keartin 17 gene mutation in patients with Steatocystoma multiplex. National Medical Journal of China. 2001-09.

18. Hana T, Fujimoto Wataru, Arata Jiro. Expression of Keratins (K10 \& K17) in Steatocystoma multiplex, eruptive vellus hair cyst and epidermoid and trichilemmal cysts. American Journal of Dermatopathology 1997; 19: 250-53.

19. Plewig G, Wolf HH, Braun-Falco O. Steatocystoma multiplex; anatomy reevaluation, electron microscopy and autoradiography. Arch Dermatol Res 1982; 272(3-4): 363-380.

20. Park KY, Oh KK, Noh TW. Steatocystoma multiplex: Mammographic and Sonographic manifestations. AJR 2003; 180: 27.

21. Karen JK, Heller M, Wee SA, Mikkilineni R. Eruptive vellus hair cysts. Dermatology online journal 13(1):1. 